УДК 616.89-008.441.13-055.2

Для цитирования: Уманская П.С., Агарков А.П. Формирование и течение алкоголизма у молодых женщин, перенесших алкогольный психоз. Сибирский вестник психиатрии и наркологии. 2018; 3 (100): 27-33. https://doi.org/10.26617/18103111-2018-3(100)-27-33

\title{
Формирование и течение алкоголизма у молодых женщин, перенесших алкогольный психоз
}

\author{
Уманская П.С. ${ }^{1}$, Агарков А.П. ${ }^{2}$ \\ ${ }^{1}$ Областной наркологический диспансер \\ Россия, 625003, Тюмень, ул. Семакова, д. 11 \\ ${ }^{2}$ Сибирский государственный медицинский университет \\ Россия, 634050, Томск, Московский тракт, 2
}

\section{PEЗЮME}

В последние десятилетия возрастает число женщин, страдающих алкоголизмом, во многих экономически развитых странах мира. Темп формирования алкоголизма у женщин является предметом дискуссии между специалистами. Исследователи сообщают как о большей скорости развития болезни среди женщин в сравнении с мужчинами, так и о невозможности точно измерить величину этого показателя в силу субъективных и объективных причин. По мнению различных авторов, в настоящее время число женщин с алкогольной зависимостью продолжает повышаться, но социальнодемографические и клинические характеристики болезненного процесса у женщин, состоящих на наркологическом учёте, изучены недостаточно, несмотря на имеющиеся публикации. В связи с вышесказанным актуальность проводимого исследования достаточно высока. Целью данного исследования, проведенного на базе Тюменского областного наркологического диспансера в отделении неотложной наркологической помощи, является выявление особенностей формирования и течения алкогольной зависимости у молодых женщин, перенесших алкогольный психоз. Изучаемую выборку составили 126 пациенток, из числа проходивших стационарное лечение по поводу алкогольных психозов в отделении неотложной наркологической помощи г. Тюмени. Результаты. Женщины в преобладающем большинстве начинают достаточно поздно употреблять спиртные напитки (в 18-20 лет), а начало систематической алкоголизации у них отмечено через продолжительный период времени и приходится на возраст 26 лет и старше. Первая стадия алкоголизма у большей части исследуемых женщин длилась более 4 лет, но не превышала 7 лет, а продолжительность второй стадии не отмечалась большой длительностью и зачастую составляла до 3 лет. В большинстве случаев алкогольные психозы у женщин развивались через 6-10 лет от формирования зависимости от алкоголя. Отмечен большой процент наследственной отягощенности по наркологическим и психическим заболеваниям среди обследованных женщин. Выводы. В связи с достаточно быстрым формирование и течением женского алкоголизма необходимо проводить своевременную профилактику алкоголизма у женщин молодого возраста, используя комплекс социальных и медицинских мероприятий.

Ключевые слова: формирование алкоголизма, течение алкоголизма, алкогольный делирий, женщины молодого возраста, алкоголь, наследственность.

\section{ВВЕДЕНИЕ}

Согласно данным статистики, в последние десятилетия растет число женщин, страдающих алкоголизмом, в России, как и во многих экономически развитых странах [Семке В.Я. и др., 1992; Иванова С.А. и др., 2002]. В ряде из них число злоупотребляющих алкоголем женщин повышается гораздо быстрее, чем число злоупотребляющих алкоголем мужчин (Office of Applied Studies, 2007). Соотношение алкоголизирующихся женщин и мужчин колеблется в широком диапазоне. Так, в Советском Союзе соотношение больных алкоголизмом женщин и мужчин варьировало от 1:9,8 до 1:12,6 [Гофман А.Г., Куприянов А.Т., 1977]. По сообщениям Н.Н. Иванца [2006], в Российской Федерации соотношение учтенных больных алкоголизмом женщин и мужчин в 1991 г. составило 1:9, в 1995 г. - 1:6. В соответствии с данными ГЛПУ Тюменской области «Областной наркологический диспансер (отделение неотложной наркологической помощи)», на 2005 г. данное соотношение соответствует 1:5, что совпадает с приводимыми данными других авторов [Анисимова Н.А., Куташов В.А., 2016].
Согласно последним опубликованным данным [Ишков Ю.В., Никонова О.А., 2013], в 2013 г. соотношение больных алкоголизмом женщин к мужчинам составляет $1: 3$, т. е. число женщин, страдающих алкоголизмом, постоянно и неуклонно растет.

Темп формирования алкоголизма у женщин является предметом острой дискуссии между специалистами [Корнетов Н.А., Губерник В.Я., Самохвалов В.П., 1985; Кравченко С.Л., 2000]. С.Л. Кравченко [2002] в своем исследовании сообщает как о большей скорости развития болезни в сравнении с мужчинами, так и о невозможности точно измерить величину этого показателя в силу субъективных и объективных причин. Большинство исследователей отмечают ускоренное развитие алкоголизма у молодых женщин в отличие от мужчин. Данный факт значительно чаще встречается в работах исследователей, основанных на обследовании госпитализированных в стационарные отделения больных [Стрельчук И.В., 1973; Deshaies G., 1963; Nachin C., 1963], и реже обсуждается при изучении пациентов в амбулаторных условиях [Литманович А.А., 1966; Горденя Ф.Ф., 1974]. 
Развитию алкоголизма у женщин посвящен целый ряд работ [Штырков А.Г., 2002; Курьянова Н.Н., 2005; Кисель Н.И., Бохан Н.А., Мандель А.И., 2011; Кривулин Е.Н., Мингазов А.Х., Байнова Н.А., 2011; Власова Л.В., Кучеренко Н.Н., Сафронова Д.Я., Красникова И.М., 2014; Шайдукова Л.К., Гареева Г.А., 2016]. Показано, что при возникновении алкоголизма у молодых женщин алкогольная болезнь развивается злокачественно [Веретило Л.В., Трусова А.В., Ерышев О.Ф. и др., 2011] и соответствует развитию алкоголизма у мужчин [Князева Т.М., Шапиро Ю.Г., 2006]. По мнению А.Г. Гофмана [2003], алкоголизм формируется у женщин позднее, чем у мужчин, так как позже начинается систематическое потребление спиртных напитков.

Сведения об особенностях алкоголизма у женщин весьма противоречивы. По данным Э.А. Бабаяна, М.Х. Гонопольского [1987], Г.М. Энтина [1990], у женщин отмечается более тяжелое и злокачественное течение алкоголизма. В противовес вышеизложенному исследования Л.К. Шайдуковой [1996], В.Б. Альтшулера [2010] доказывают, что это мнение несколько преувеличено и основано на общественной нетерпимости к женскому пьянству.

По мнению различных авторов, в настоящее время число женщин с алкогольной зависимостью продолжает возрастать [Гузиков Б.М., 1988; Софронов А.Г., Николкина Ю.А., 2011]. Существующие государственные формы учёта наркологических пациентов содержат ограниченное количество показателей для детального анализа данного контингента. Социально-демографические и клинические характеристики болезненного процесса у женщин, состоящих на наркологическом учёте, изучены недостаточно, несмотря на имеющиеся публикации [Клейберг Ю.А., 2004; Константинова В.В., Яровинская А.В., 2010]. В связи с вышесказанным актуальность проводимого исследования оценивается как достаточно высокая.

Целью данного исследования, проведенного на базе Тюменского областного наркологического диспансера в отделении неотложной наркологической помощи, было выявление особенностей формирования и течения алкогольной зависимости у молодых женщин, перенесших алкогольный психоз.

\section{МАТЕРИАЛЫ И МЕТОДЫ}

Для исследования нами были отобраны молодые женщины, поступившие в отделение неотложной наркологической помощи г. Тюмени в период с 2011 по 2014 г. Изучаемую выборку составили 126 пациенток, из числа проходивших стационарное лечение по поводу алкогольных психозов в отделении неотложной наркологической помощи г. Тюмени. Подбор больных в ходе проведения исследования осуществлялся выборочно, с учетом разработанных нами критериев включения.

Критериями включения в исследование служили: 1) возраст пациентов от 25 до 44 лет (лица молодого возраста по классификации ВОЗ [2012 г.]); 2) установленный диагноз психических и поведенческих расстройств вследствие употребления алкоголя, синдром зависимости, II стадия; 3) установленный диагноз алкогольного психоза (острый алкогольный делирий, острый алкогольный галлюциноз, структурно-сложный психоз).

Клинический диагноз больным был выставлен в соответствии с Международной классификацией болезней 10-го пересмотра [Психические расстройства и расстройства поведения, класс V, адаптированный для использования в Российской Федерации. М.: МЗ РФ, 1998].

Все обследованные пациенты в возрасте от 25 до 44 лет получали традиционную медикаментозную терапию в соответствии с медицинскими стандартами оказания наркологической помощи (приказ М3 РФ № 323 от 21.11.2011 г. «Об основах охраны здоровья граждан в Российской Федерации»).

В ходе работы были использованы следующие методы исследования: клинико-психопатологический, клинико-динамический, статистический. Обработка результатов исследования проводилась методами многомерной статистики, корреляционного анализа; достоверность полученных данных оценивалась с применением u-критерия Манна-Уитни (для неравномерных выборок) и t-критерия Стьюдента (для равномерных выборок в исключительных случаях).

Систематизация полученных данных клинического исследования больных осуществлялась с применением разработанной и модифицированной нами в связи с особенностями изучаемого контингента (на кафедре психиатрии, наркологии и психотерапии ФПК и ППС Тюменской государственной медицинской академии) «Базисной карты наркологического больного, перенесшего острый алкогольный психоз».

Исследование проводилось путем опроса больных, их родственников, осмотра пациентов, заполнения статистических карт пациентов. Работая в стационаре, один из авторов статьи в большинстве случаев лично принимал участие в госпитализации больных и последующем их лечении, наблюдал за клинической динамикой течения алкогольного психоза и выходом пациентов из него.

\section{РЕЗУЛЬТАТЫ И ОБСУЖДЕНИЕ}

В исследуемую группу было включено 126 пациенток, средний возраст которых составил $35,44 \pm 4,8$ года, имеющих вторую стадию алкоголизма, находящихся на стационарном лечении по поводу алкогольных психозов.

Все исследуемые были разделены на 4 группы по возрастному показателю (25-30 лет, 31-35 лет, 3640 лет, 41-44 года). Как показано на рисунке 1, наибольшее число обследованных больных алкогольными психозами женщин приходилось на возраст 31-35 лет $(35,7 \%)$ и 41-44 года $(27,0 \%)$. Меньшее количество пациенток приходилось на возрастные группы 25-30-летних $(21,4 \%)$ и 36-40-летних $(15,9 \%)$. 


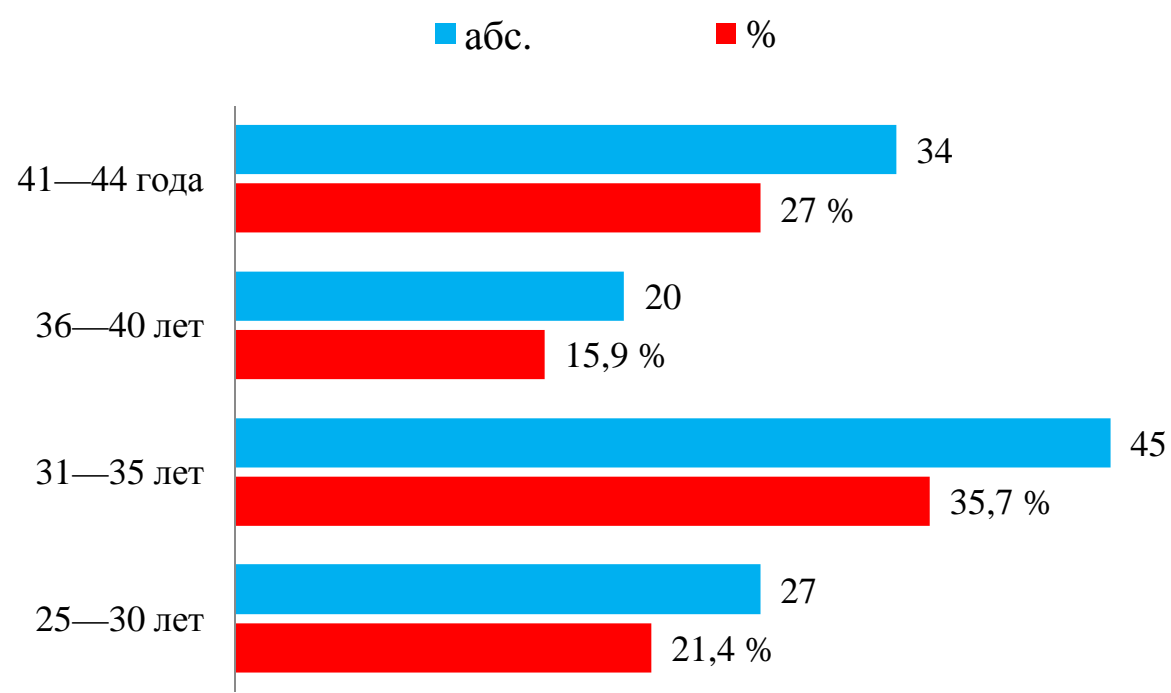

\section{Р и с у н о к 1. Распределение пациентов по возрастным группам}

У 22,8\% исследуемых наследственность не была отягощена по алкоголизму, наркомании или психическим заболеваниям (табл. 1). Наличие отягощенной наследственности со стороны отца было отмечено у 22,3\% пациентов, со стороны матери - у 8,1 $\%$. У $13,3 \%$ пациентов наследственность была отягощена со стороны дальних родственников (двоюродные братья и сестры, дед или бабка и т. д.), со стороны братьев или сестер - у 6,1\%. У 0,6\% исследуемых наследственность была отягощена психическими заболеваниями ближайших родственников и у 25,5\% пациенток не было никаких сведений о наследственной отягощенности по наркологическим и психическим заболеваниям.

Т а б л и ц а 1

Наследственная отягощенность по алкоголизму, наркоманиям и психическим заболеваниям

\begin{tabular}{|l|c|c|}
\hline \multirow{2}{*}{ Наследственная отягощенность } & \multicolumn{2}{|c|}{$\begin{array}{c}\text { Количество } \\
\text { признаков } \\
\text { у женщин (n=197) }\end{array}$} \\
\cline { 2 - 3 } & абс. & $\%$ \\
\hline Отягощена со стороны отца & 44 & 22,3 \\
\hline $\begin{array}{l}\text { Не известно о наличии отягощенной } \\
\text { наследственности }\end{array}$ & 53 & 26,9 \\
\hline $\begin{array}{l}\text { Отягощена со стороны дальних род- } \\
\text { ственников }\end{array}$ & 26 & 13,2 \\
\hline Отягощена со стороны матери & 16 & 8,1 \\
\hline $\begin{array}{l}\text { Отягощена со стороны братьев или } \\
\text { сестер }\end{array}$ & 12 & 6,1 \\
\hline $\begin{array}{l}\text { Наследственность отягощена психи- } \\
\text { ческим заболеванием }\end{array}$ & 1 & 0,6 \\
\hline Наследственность не отягощена & 45 & 22,8 \\
\hline
\end{tabular}

У изучаемого контингента имели место следующие нозологические формы алкогольных психозов. Диагнозы в обследованных группах формулировались согласно Международной классификации болезней 10-го пересмотра «Психические расстройства и расстройства поведения, вызванные употреблением алкоголя, синдром отмены с делирием: делирий классический, типичный (F10.402), делирий с судорожными припадками (F10.412), абортивный делирий (F10.452), острый алкогольный галлюциноз или психотическое расстройство преимущественно галлюцинаторное (F10.522), структурно сложный психоз или психотическое расстройство преимущественно полиморфное (F10.532). Таким образом, мы получили следующую общую нозологическую структуру алкогольных психозов у обследуемых лиц.

Преобладающему количеству пациенток $(57,1 \%)$ был выставлен диагноз «Алкогольный делирий» (табл. 2). В 2,3 раза реже $(24,6 \%)$ у обследованных больных имел место «Острый алкогольный галлюциноз». У 18,3\% пациентов был диагностирован структурно-сложный алкогольный психоз.

Т а бл и ц а 2

Клинико-нозологические формы алкогольных психозов по группам обследуемых

\begin{tabular}{|l|c|c|}
\hline \multirow{2}{*}{\multicolumn{1}{|c|}{ Нозологическая форма }} & \multicolumn{2}{|c|}{ Женщины (n=126) } \\
\cline { 2 - 3 } & aбс. & $\%$ \\
\hline Алкогольный делирий & 72 & 57,1 \\
\hline Острый алкогольный галлюцино3 & 31 & 24,6 \\
\hline Структурно-сложный психоз & 23 & 18,3 \\
\hline
\end{tabular}

Таким образом, алкогольный делирий являлся наиболее частой формой алкогольных психозов у исследуемых. Количество больных острым алкогольным галлюцинозом лишь незначительно превалировало над количеством пациентов со структурно-сложным психозом.

При проведении исследования выявлено, что из 126 пациентов преобладающее большинство $(79,4 \%)$ начали употреблять спиртные напитки еще до наступления совершеннолетия, 19,0\% больных начали алкоголизироваться в 18-20 лет и только 1,6\% - после 20 лет.

Возраст начала систематической алкоголизации у пациенток также варьировался в различных воз- 
растных пределах. Под систематической алкоголизацией, согласно Э.Е. Бехтелю [1986], подразумевается употребление 200-300 мл (максимум 500 мл) водки 1-2 раза в неделю.

Большее число женщин $(38,9 \%)$ начали систематически употреблять алкоголь в 21-25 лет, 30,2\% в 18-20 лет. Наименьшее количество пациенток $(19,8 \%$ и $11,1 \%)$ стали прибегать к приему алкогольных напитков в 26-30 лет и в 31 год и старше соответственно.

Более чем у половины обследованных женщин $(55,6 \%)$ первая стадия алкоголизма характеризовалась длительностью 4-5 лет. В 2,2 раза реже $(25,4 \%)$ у женщин длительность первой стадии алкоголизма составляла 6-7 лет. У наименьшего числа женщин $(14,3 \%$ и 4,7\%) длительность первой стадии была до 3 и 8-9 лет соответственно. Вторая стадия алкоголизма наиболее часто (36,5\%) у женщин продолжалась до 5 лет. У незначительно меньшего количества пациенток $(27,8 \%$ и $15,9 \%)$ продолжительность второй стадии алкоголизма составила до 3 и до 10 лет соответственно. Лишь у минимальной доли исследуемых $(7,1 \%)$ вторая стадия продолжалась более 10 лет.

У большинства исследуемых $(42,1 \%)$ алкогольный абстинентный синдром сформировался в скором времени после начала алкоголизации в возрасте 21-25 лет. Около трети женщин $(30,2 \%)$ отмечали начало похмельного синдрома в возрасте 26-30 лет. С более редкой частотой абстинентный синдром был сформирован после 31 года $(22,1 \%)$ и в $18-20$ лет $(5,6 \%)$.

Длительность течения алкоголизма до наступления первого психоза состаляет до 10 лет и более. Более половины алкогольных психозов $(53,2 \%)$ наблюдается среди исследуемых, алкоголизирующихся в течение 6-10 лет. У 29,3\% пациентов первый алкогольный психоз был отмечен при длительности течения алкоголизма более 10 лет и у $17,5 \%$ до 5 лет.

Данные о возрастном распределении больных при манифестации первого алкогольного психоза представлены в таблице 3 .

$$
\text { Т а бл и ц а } 3
$$

Возраст больных при манифестации первого алкогольного психоза

\begin{tabular}{|l|c|c|}
\hline \multirow{2}{*}{ Возраст больных, лет } & \multicolumn{2}{|c|}{ Женщины $(\mathrm{n}=126)$} \\
\cline { 2 - 3 } & абс. & $\%$ \\
\hline $25-30$ лет & 51 & 40,5 \\
\hline $31-35$ лет & 31 & 24,6 \\
\hline $36-40$ лет & 23 & 18,3 \\
\hline $41-44$ года & 21 & 16,7 \\
\hline
\end{tabular}

Большинство впервые манифестировавших алкогольных психозов приходится на возраст 25-30 лет (40,5\%). В 1,6 раза реже $(24,6 \%)$ первый алкогольный психоз возникал в возрасте 31-35 лет и в 2,2 раза реже $(18,3 \%)$ в возрастной группе 36-40 лет. Наименьшее количество $(16,7 \%)$ впервые манифестировавших алкогольных психозов в нашем исследовании было отмечено в возрасте 41-44 года.

\section{ВЫВОДЫ}

Из вышесказанного следует, что формирование и течение алкогольной зависимости у женщин молодого возраста, перенесших алкогольный психоз, имеют определенные особенности. Так, преобладающая часть женщин начинает достаточно поздно употреблять спиртные напитки (в возрасте 18-20 лет), а начало систематической алкоголизации у них отмечено через продолжительный период времени и приходится на возраст 26 лет и старше. В нашем исследовании было отмечено, что первая стадия алкоголизма у большей части исследуемых женщин длилась более 4 лет, но не превышала 7 лет, а продолжительность второй стадии не характеризовалась большой длительностью и зачастую составляла до 3 лет.

В ходе проведения исследования было отмечено, что у женщин в большинстве случаев алкогольные психозы развивались через 6-10 лет с начала формирования зависимости от алкоголя. Также среди обследованных женщин зафиксирован большой процент наследственной отягощенности по наркологическим и психическим заболеваниям.

Таким образом, в ходе проведения исследования выявлены особенности формирования и течения алкогольной болезни у женщин, что обосновывает научную новизну работы и ее актуальность в условиях современной ситуации роста алкоголизма и возросшей частоты алкогольных психозов у женщин молодого возраста.

\section{КОНФЛИКТ ИНТЕРЕСОВ}

Авторы заявляют об отсутствии конфликта интересов в связи с публикацией данной статьи.

\section{ИСТОЧНИК ФИНАНСИРОВАНИЯ}

Авторы заявляют об отсутствии финансирования при проведении исследования.

\section{СООТВЕТСТВИЕ ПРИНЦИПАМ ЭТИКИ}

Работа соответствует этическим стандартам Хельсинской декларации ВМА (протокол заседания этического комитета ГБОУ ВПО Тюменской государственной медицинской академии Минздрава России, протокол № 53 заседания Комитета по этике от 06.11.2013 г.).

\section{ЛИТЕРАТУРА}

1. Альтшулер В.Б. Алкоголизм. М.: ГЭОТАР-Медиа, 2010: 264.

2. Анисимова Н.А., Куташов В.А. К вопросу об алкоголизме у женщин. Центральный научный вестник. 2016; 1 (15): 3-5.

3. Бабаян Э.А., Гонопольский М.Х. Наркология. М.: Медицина, 1987: 336.

4. Веретило Л.В., Трусова А.В., Ерышев О.Ф., Рыбакова К.В., Ерошин С.П., Крупицкий Е.М. Клинические варианты злокачественного течения алкогольной зависимости. Обозрение психиатрии и медицинской психологии им. В.М. Бехтерева. 2011; 4: 14-19.

5. Власова Л.В., Кучеренко Н.Н., Сафронова Д.Я., Красникова И.М. Алкоголизм у женщин и факторы его предопределяющие. Современная медицина: актуальные вопросы. 2014; 31: 73-77.

6. Горденя Ф.Ф. Особенности формирования и течения алкоголизма у женщин. Клинические проблемы алкоголизма. Л., 1974: 33-40.

7. Гофман А.Г., Куприянов А.Т. О сходстве и различии алкоголизма у мужчин и женщин по данным диспансера. Про- 
филактика, клиника, лечение алкоголизма и наркоманий, организация наркологической помощи. М.: МЗ РСФСР, 1977: 111-123.

8. Гофман А.Г. Клиническая наркология. М.: Миклош, 2003 215 .

9. Гузиков Б.М., Мейроян А.А. Алкоголизм у женщин. Л. Медицина, 1988: 224.

10. Иванец Н.Н. [и др.] Психиатрия и наркология: учебник. М ГЭОТАР-Медиа, 2006.

11. Иванова С.А., Ветлугина Т.П., Бохан Н.А., Эпштейн О.И. Иммунобиология аддиктивных расстройств: механизмы психонейроиммуномодуляции. Сибирский вестник психиатрии и наркологии. 2002; 1 (23): 50-57.

12. Ишков Ю.В., Никонова О.А. Профилактика и меры борьбь с суицидами у женщин молодого возраста, страдающих алкоголизмом (на примере Астраханского региона. Вестник Астраханского государственного технического универсиmema. 2013; 2 (56): 108-114.

13. Князева Т.М., Шапиро Ю.Г. Социоклинический анализ женского алкоголизма. Вопросы наркологии. 2006; 3: 43-48.

14. Кисель Н.И., Бохан Н.А., Мандель А.И., Анкудинова И.Э., Ляшенко Г.П. Клиническая динамика алкогольной зависимости у женщин с преморбидными личностными расстройствами. Сибирский вестник психиатрии и наркологии. 2011 3 (66): 32-34.

15. Клейберг Ю.А. Социальная психология девиантного поведения. М., 2004: 43-44.

16. Константинова В.В., Яровинская А.В. Ценностные ориентации и социально-психологическая адаптация больных алкоголизмом. Актуальные проблемы гуманитарных и есте ственных наук. 2010; 9: 373-381.

17. Корнетов Н.А., Губерник В.Я., Самохвалов В.П. Возрастной патоморфоз темпа прогредиентности алкоголизма у больных, перенесших алкогольный делирий. Журнал невропатологии и психиатрии. 1985; 2: 259-262.

18. Кравченко С.Л. Ремиссии и рецидивы алкоголизма у женщин с разной прогредиентностью заболевания. Bonросы наркологии. 2002; 4: 8-15.

19. Кравченко С.Л. Соотношение преморбидных факторов и прогредиентности алкоголизма у женщин. Вопросы наркопогии. 2002; 5: 26-31.
20. Кривулин Е.Н. Мингазов А.Х., Байнова Н.А. К вопросу о профилактике алкоголизма у женщин в разные возрастные периоды. Тюменский медицинский журнал. 2011; 2: 39-40.

21. Курьянова Н.Н. О формировании алкоголизма у женщин Астрахани. Вопросы наркологии. 2005. № 6: 68-71

22. Литманович А.А. Сравнительная характеристика различных методов противоалкогольной терапии в амбулаторных условиях. Вопросы психиатрии и неврологии: сб. трудов Ленинградского научного общества невропатологов и психиатров. Л., 1966; вып ХІІ: 420-426.

23. Семке В.Я., Галактионов О.К., Мандель А.И., Бохан Н.А., Мещеряков Л.В. Алкоголизм: региональный аспект / под общ. ред. В.Я. Семке. Томск, 1992: 217.

24. Софронов А.Г., Николкина Ю.А. Социальнодемографические, клинические характеристики женщин, страдающих алкогольной зависимостью, находящихся на динамическом наблюдении в наркологическом диспансере. Наркология. 2011; 12: 46-51.

25. Стрельчук И.В. Алкоголь - враг здоровья!. М., 1973

26. Шайдукова Л.К. Особенности формирования и течения алкоголизма у женщин: автореф. дис. ... д. м. н. М., 1996.

27. Шайдукова Л.К., Гареева Г.А. Современная проблематика алкоголизма у женщин: этнокультуральный, социальнодемографический, наследственно-генетический, преморбидно-патохарактерологический аспекты. Наркология. 2016; 15, 1 (169): 73-78.

28. Штырков А.Г. Алкоголизм у женщин с эпилептоидным складом характера. Вопросы наркологии. 2002; 5: 47-51.

29. Энтин Г.М. Лечение алкоголизма. М.: Медицина, 1990: 416

30. Deshaies G. L'alcoolisme de la femme. Revue de l'Alcoolisme. 1963; 9: 235-247.

31. Nachin Ch. L'alcoolisme feminin. Rew. de Alcoolisme. 1963; 9 : $248-262$.

32. Office of Applied Studies. Results from the 2006 National Survey on Drug Use and Health: National findings (DHHS Publication No. SMA 074293, NSDUH Series H-32). Rockville, MD: Substance Abuse and Mental Health Services Administration, 2007.

Поступила в редакцию 16.04.2018 Утверждена к печати 25.06.2018

Уманская Полина Станиславовна, к.м.н., врач психиатр-нарколог отделения неотложной наркологической помощи.

Агарков Александр Прокопьевич, д.м.н., проф., заслуженный врач России, профессор кафедры психиатрии, наркологии и психотерапии.

Уманская Полина Станиславовна, umanskie@gmail.com

For citation: Umanskaya P.S., Agarkov A.P. Formation and course of alcoholism in young women who have experienced alcoholic psychosis. Siberian Herald of Psychiatry and Addiction Psychiatry. 2018; 3 (100): 27-33. https://doi.org/10.26617/1810-31112018-3(100)-27-33

\title{
Formation and course of alcoholism in young women who have experienced alcoholic psychosis
}

\section{Umanskaya P.S. ${ }^{1}$, Agarkov A.P. ${ }^{2}$}

\author{
${ }^{1}$ Regional Narcological Dispensary \\ Semakov Street 11, 625003, Tyumen, Russian Federation \\ ${ }^{2}$ Siberian State Medical University \\ Moskovsky Trakt 2, 634050, Tomsk, Russian Federation
}

\section{ABSTRACT}

In recent decades, the number of women suffering from alcoholism is increasing in many economically developed countries. The rate of formation of alcoholism in women is a matter of discussion between specialists. Researchers report both a higher rate of development of the disease in comparison with men, and the impossibility to measure accurately the value of this indicator owing to subjective and objective causes. According to various authors, at present the number of women with alcohol dependence continues to increase, but sociodemographic and clinical characteristics of the morbid process among women who are registered are not enough studied, despite the available publications. Hence, the relevance of the research is quite high. Objective of this study conducted on the basis of the Tyumen Regional Narcological Dispensary in the Department of Narcological Emergency is to identify the features of the formation and course of alcohol dependence in young women who have experienced alcoholic psycho- 
sis. The sample studied is made up of 126 patients, among those who undergo inpatient treatment for alcoholic psychoses in the Unit of Narcological Emergency of Tyumen. Results. Women, for the most part, start drinking alcoholic beverages quite late (at the age of 18-20 years), and the beginning of systematic alcoholization in them is noted after a long period of time and falls on the age of 26 years and older. In our study, it is noted that the first stage of alcoholism in most of the women studied lasts more than 4 years, but does not exceed 7 years, and the duration of stage II is not marked with a great duration and, often, is up to 3 years. During the study, it is noted that in most women, alcoholic psychoses develop in 6-10 years from the formation of alcohol dependence. Also, during the study, a large percentage of family histories of narcological and mental illness among the women examined is noted. Conclusions. In connection with the rather rapid formation and course of alcoholism in women, it is necessary to conduct timely prevention of alcoholism in young women, using a set of social and medical measures.

Keywords: formation of alcoholism, alcoholism, alcohol delirium, young women, alcohol, heredity.

\section{REFERENCES}

1. Altshuler V.B. Alkogolizm [Alcoholism]. Moscow: GEOTARMedia. 2010: 264 (in Russian).

2. Anisimova N.A., Kutashov V.A. K voprosu ob alkogolizme u zhenshchin [On the issue of alcoholism in women]. Tsentralnyy nauchnyy vestnik - Central Scientific Bulletin. 2016; 1 (15): 3-5 (in Russian).

3. Babayan E.A., Gonopolsky M.Kh. Narkologiya [Narcology]. Moscow: Meditsina. 1987: 336 (in Russian).

4. Veretilo L.V., Trusova A.V., Eryshev O.F., Rybakova K.V., Eroshin S.P., Krupitsky E.M. Klinicheskiye varianty zlokachestvennogo techeniya alkogolnoy zavisimosti [Clinical variants of malignant course of alcoholic dependence]. Obozreniye psikhiatrii $i$ meditsinskoy psikhologii im. V.M. Bekhtereva V.M. Bekhterev Review of Psychiatry and Medical Psychology. 2011; 4: 14-19 (in Russian)

5. Vlasova L.V., Kucherenko N.N., Safronova D.Ya., Krasnikova I.M. Alkogolizm u zhenshchin i faktory ego predopredelyayushchiye [Alcoholism in women and its determinants]. Sovremennaya meditsina: aktualnyye voprosy - Current MedicineRelevant Questions. 2014; 31: 73-77 (in Russian).

6. Gordenya F.F. Osobennosti formirovaniya i techeniya alkogolizma $\mathrm{u}$ zhenshchin [Peculiarities of formation and course of alcoholism in women]. Klinicheskiye problemy alkogolizma. Leningrad, 1974: 33-40 (in Russian).

7. Hofmann A.G., Kupriyanov A.T. O skhodstve i razlichii alkogolizma u muzhchin i zhenshchin po dannym dispansera [On the similarity and differences in alcoholism in men and women according to the dispensary]. Profilaktika, klinika, lecheniye alkogolizma i narkomaniy, organizatsiya narkologicheskoy pomoshchi. Moscow: MZ RSFSR. 1977: 111-123 (in Russian).

8. Hofmann A.G. Klinicheskaya narkologiya [Clinical narcology]. Moscow: Miklosh. 2003: 215 (in Russian).

9. Guzikov B.M., Meyroyan A.A. Alkogolizm u zhenshchin [A1coholism in women]. Leningrad: Meditsina. 1988: 224 (in Russian).

10. Ivanets N.N. [i dr.] Psikhiatriya i narkologiya: uchebnik [Psychiatry and narcology: textbook]. Moscow: GEOTAR-Media. 2006 (in Russian).

11. Ivanova S.A., Vetlugina T.P., Bokhan N.A., Epstain O.I. Immunobiology of addictive disorders: mechanisms of psychoneuroimmunomodulation. Sibirskii vestnik psikhiatrii $i$ narkologii Siberian Herald of Psychiatry and Addiction Psychiatry. 2002; 1 (23): 50-57. (in Russian).

12. Ishkov Yu.V., Nikonova O.A. Profilaktika i mery borby s suitsidami u zhenshchin molodogo vozrasta. stradayushchikh alkogolizmom (na primere Astrakhanskogo regiona [Prevention and measures to combat suicide in young women suffering from alcoholism (by the example of the Astrakhan region)]. Vestnik Astrakhanskogo gosudarstvennogo tekhnicheskogo universiteta - Bulletin of Astrakhan State Technic University. 2013; 2 (56) 108-114 (in Russian).

13. Knyazeva T.M., Shapiro Yu.G. Sotsioklinicheskiy analiz zhenskogo alkogolizma [Socio-clinical analysis of female alcoholism]. Voprosy narkologii - Journal of Addiction Problems. 2006; 3: 43-48 (in Russian)

14. Kisel N.I., Bokhan N.A., Mandel A.I., Ankudinova I.E., Lyashenko G.P. Klinicheskaya dinamika alkogolnoy zavisimosti $\mathrm{u}$ zhenshchin s premorbidnymi lichnostnymi rasstroystvami. Sibirskiy vestnik psikhiatrii i narkologii [Clinical dynamics of alcohol dependence in women with premorbid personality disorders]. Sibirskiy vestnik psikhiatrii i narkologii - Siberian Herald of Psychiatry and Addiction Psychiatry. 2011; 3 (66): 32-34 (in Russian).

15. Kleyberg Yu.A. Sotsialnaya psikhologiya deviantnogo povedeniy [Social psychology of deviant behavior]. Moscow, 2004: 43-44 (in Russian).

16. Konstantinova V.V., Yarovinskaya A.V. Tsennostnyye orientatsii i sotsialno-psikhologicheskaya adaptatsiya bolnykh alkogolizmom [Value orientations and socio-psychological adaptation of patients with alcoholism]. Aktualnyye problemy gumanitarnykh $i$ estestvennykh nauk - Relevant Problems of Humanitarian and Natural Sciences. 2010; 9: 373-381 (in Russian).

17. Kornetov N.A., Gubernik V.Ya., Samokhvalov V.P. Vozrastnoy patomorfoz tempa progrediyentnosti alkoglizma u bolnykh. perenesshikh alkogolnyy deliriy [Age-related pathomorphism of the rate of alcoholism progression in patients after alcohol delirium]. Zhurnal nevropatologii i psikhiatrii - Journal of Neurology and Psychiatry. 1985; 2: 259-262 (in Russian).

18. Kravchenko S.L. Remissii i retsidivy alkogolizma u zhenshchin s raznoy progrediyentnostyu zabolevaniya [Remissions and relapses of alcoholism in women with different disease progresses]. Voprosy narkologii - Journal of Addiction Problems. 2002; 4: 8-15 (in Russian).

19. Kravchenko S.L. Sootnosheniye premorbidnykh faktorov i progrediyentnosti alkogolizma u zhenshchin [The ratio of premorbid factors and progredientity of alcoholism in women]. Voprosy narkologii - Journal of Addiction Problems. 2002; 5: 26-31 (in Russian).

20. Krivulin E.N. Mingazov A.Kh., Baynova N.A. K voprosu o profilaktike alkogolizma u zhenshchin $\mathrm{v}$ raznyye vozrastnyye periody [To the question of the prevention of alcoholism in women in different age periods]. Tyumenskiy meditsinskiy zhurnal - Tymen Medical Journal. 2011; 2: 39-40 (in Russian).

21. Kurianova N.N. O formirovanii alkogolizma u zhenshchin Astrakhani [On the formation of alcoholism in women of Astrakhan]. Voprosy narkologii - Journal of Addiction Problems. 2005; 6: 68-71 (in Russian).

22. Litmanovich A.A. Sravnitelnaya kharakteristika razlichnykh metodov protivoalkogolnoy terapii v ambulatornykh usloviyakh [Comparative characteristics of various methods of antialcohol therapy in outpatient settings]. Voprosy psikhiatrii i nevrologii: sb. trudov Leningradskogo nauchnogo obshchestva nevropatologov i psikhiatrov. L., 1966; vyp XII: 420-426 (in Russian).

23. Semke V.Ya., Galaktionov O.K., Mandel A.I., Bokhan N.A., Meshcheryakov L.V. [Alcoholism: regional aspect]. V.Ya. Semke, ed. Tomsk, 1992: 217 (in Russian).

24. Sofronov A.G., Nikolkina Yu.A. Sotsialno-demograficheskiye, klinicheskiye kharakteristiki zhenshchin, stradayushchikh alkogolnoy zavisimostyu. nakhodyashchikhsya na dinamicheskom nablyudenii $\mathrm{v}$ narkologicheskom dispansere [Sociodemographic, clinical characteristics of women with alcohol dependence who are under dynamic observation in the narcological dispensary]. Narkologiya - Narcology. 2011; 12: 46-51 (in Russian).

25. Strelchuk I.V. Alkogol - vrag zdorovia! [Alcohol - the enemy of health!]. M., 1973 (in Russian)

26. Shaydukova L.K. Osobennosti formirovaniya $i$ techeniya alkogolizma u zhenshchin [Peculiarities of formation and course of alcoholism in women]: avtoref. dis. ... d.m.n. Moscow, 1996 (in Russian).

27. Shaydukova L.K., Gareyeva G.A. Sovremennaya problematika alkogolizma u zhenshchin: etnokulturalnyy. sotsialnodemo- 
graficheskiy. nasledstvenno-geneticheskiy. premorbidnopatokharakterologicheskiy aspekty [Modern problems of alcoholism in women: ethnocultural, socio-demographic, hereditarygenetic, premorbid-patoharakterologicheskie aspects]

Narkologiya - Narcology. 2016; 15.1 (169): 73-78 (in Russian).

28. Shtyrkov A.G. Alkogolizm u zhenshchin s epileptoidnym skladom kharaktera [Alcoholism in women with an epileptoid character warehouse]. Voprosy narkologii - Journal of Addiction Problems. 2002; 5: 47-51 (in Russian).

29. Entin G.M. Lecheniye alkogolizma [Therapy of alcoholism] Moscow: Meditsina. 1990: 416 (in Russian).
30. Deshaies G. L'alcoolisme de la femme. Revue de l'Alcoolisme. 1963; 9: 235-247.

31. Nachin Ch. L'alcoolisme feminin. Rew. de Alcoolisme. 1963; 9: 248-262.

32. Office of Applied Studies. Results from the 2006 National Survey on Drug Use and Health: National findings (DHHS Publication No. SMA 074293, NSDUH Series H-32). Rockville, MD: Substance Abuse and Mental Health Services Administration, 2007.

Received April 16.2017 Accepted June 25.2018

Umanskaya Polina S., PhD, addiction specialist of the Department of the First Narcological Aid, Regional Narcological Dispensary, Tyumen, Russian Federation.

Agarkov Alexander P., MD, Prof., Honored Physician of the Russian Federation, professor of Department of Psychiatry, Narcology and Psychotherapy, Siberian State Medical University, Tomsk, Russian Federation.

Umanskaya Polina S., umanskie@gmail.com 